\title{
Lactose Flux Occurs by Differing Mechanisms in the Colon and Jejunum of Newborn Piglets
}

\author{
ROBERT D. MURRAY, ANTON H. AILABOUNI, PRISCILLA A. POWERS, LEO A. HEITLINGER, \\ B U. K. LI, H. JUHLING MCCLUNG, AND HOWARD R. SLOAN \\ Department of Pediatrics, Section of Gastroenterology, The Ohio State University, Children's Hospital, \\ Columbus, Ohio 43205; and Department of Pediatrics, Lincoln Hospital, New York Medical College, \\ Bronx, New York 10451
}

\begin{abstract}
The unidirectional flux of 10- and 40-mM lactose was studied in newborn porcine jejunum and colon mounted in Ussing chambers. Polyethylene glycol 400 was used to measure passive paracellular permeability. The mucosal-to-serosal flux and the tissue accumulation of labeled lactose from the colon was similar to that of lactosederived glucose from the jejunum. However, only jejunum showed a lactose-stimulated increase in short-circuit current. In jejunum, glucose was the sole sugar identified in the serosal bath, whereas in colon, only intact lactose was identified. Despite colonic lactose flux, polyethylene glycol oligomers were not found in the serosal bath, suggesting that they do not share the same route of absorption. Colonic lactose transport was nonsaturable between 1 and $40 \mathrm{mM}$. Under nongradient conditions, no net colonic lactose transport was observed. Cumulatively, these data suggest that the colon, unlike the jejunum, does not contain a glucosegalactose sodium cotransporter. The colon of the newborn piglet transports intact lactose at a flux equal to that of lactose-derived glucose by the small intestine, but by a different mechanism that is as yet undefined. (Pediatr Res 33: 568-572, 1993)
\end{abstract}

Abbreviations

$I_{\text {sc }}$, short-circuit current

PEG, polyethylene glycol

$\mathbf{R}_{t}$, tissue resistance

TLC, thin-layer chromatography

$\mathrm{J}_{\mathrm{m} \rightarrow \mathrm{s}}$, mucosal-to-serosal lactose flux

$\mathbf{J}_{\mathrm{s} \rightarrow \mathrm{m}}$, serosal-to-mucosal lactose flux

Several studies (1-5) have suggested that the colon of the human neonate, especially the premature infant, may be a major site for the digestion and assimilation of lactose. Estimates of the amount of lactose retrieved from the colon in newborns vary. Based on breath $\mathrm{H}_{2}$ measurements in human premature infants, estimates by MacLean and Fink (3) suggested that most of the ingested lactose was fermented in the colon. Subsequently, data on the rate of $\mathrm{H}_{2}$ recovery in the breath of infants after a lactose meal led to a revision of MacLean and Fink's estimates and suggested that the amount of lactose fermented may be 15 to $20 \%$ of that ingested (6). Because the daily lactose load is substantial (nearly $13 \mathrm{~g} / \mathrm{kg} / \mathrm{d}$ ), the amount passed into the colon could be nutritionally significant. Surprisingly, the newborn nei-

Received September 3, 1992; accepted January 26, 1993.

Correspondence: Robert D. Murray, M.D., Division of Gastroenterology, Columbus Children's Hospital, 700 Children's Dr., Columbus, OH 43205.

Supported by a grant from the National Institute of Child Health and Human Development, HD-21295. ther develops an osmotic diarrhea nor loses excessive amounts of carbohydrate in the stool $(2,4,5)$. Based on the available data, researchers have inferred that, as in adults, bacterial fermentation is the primary mechanism whereby the newborn salvages lactose energy that would otherwise be lost (7).

However, it has been shown that even when colonic bacterial population is low, the newborn can still recover lactose from the lumen of the colon. In vivo colonic perfusions in newborn piglets, in which the bacteria had been depleted by flushing with normal saline, demonstrated that the colonic mucosa absorbs the lactose at a rate up to 20 -fold greater than it absorbed an equimolar mixture of glucose and galactose, the monosaccharide constituents of lactose (8). This phenomenon was not the result of prior action of bacterial or colonic mucosal $\beta$-galactosidase activity; both were shown to be negligible.

In the current study, lactose uptake was compared in the jejunum and the right colon of the newborn piglet using tissues mounted in Ussing-type chambers. $\mathrm{J}_{\mathrm{m} \rightarrow \mathrm{s}}$ and appearance of carbohydrate in the serosal bath were determined, and measurements of the $I_{s c}$ and $R_{t}$ were made. Saturability of lactose absorption using mucosa-to-serosa gradients between 1- and 40-mM concentrations and the absorption of lactose under nongradient conditions were tested. PEG 400, a mixture of homologous oligomers that are insoluble in lipids, was used to determine whether diffusion through paracellular channels was enhanced by the presence of lactose $(9,10)$.

\section{MATERIALS AND METHODS}

Animal and Tissue Preparation. All studies were approved by the Animal Care and Use Committee. Newborn Yorkshire piglets ( 3 to $4 \mathrm{~d}$ old; 1.8 to $2.6 \mathrm{~kg}$ ) were obtained from the swineherdsman and delivered to the lab on the morning of the study. The piglets had been exclusively fed sow milk. Piglets were anesthetized with pentobarbital ( $35 \mathrm{mg} / \mathrm{kg}$ intraperitoneally) within $1 \mathrm{~h}$ after procurement. A midline incision was made, and the entire small and large bowel was excised. The excised gut was immersed in iced Ringer's solution containing (in mmol/L): $\mathrm{Na}^{+}, 136 ; \mathrm{K}^{+}$, 6; $\mathrm{Cl}^{-}, 130 ; \mathrm{HCO}_{3}^{-}, 14 ; \mathrm{H}_{2} \mathrm{PO}_{4}, 1.2 ; \mathrm{Ca}^{++}, 2.5 ; \mathrm{Mg}^{++}, 1.2 ; \mathrm{pH}$ 7.4 , that had been bubbled with $95 \% \mathrm{O}_{2}: 5 \% \mathrm{CO}_{2}$. Transport of the tissue to the laboratory took $1 \mathrm{~min}$. The animal was euthanized by i.v. injection of concentrated pentobarbitol. Twenty-cm segments of jejunum beginning $10 \mathrm{~cm}$ distal to the ligament of Treitz, or of right colon beginning just distal to the ileocecal valve, were opened along the antimesenteric border, stripped of serosa and longitudinal muscle, and mounted in standard Ussingtype chambers $\left(1.12-\mathrm{cm}^{2}\right.$ surface area) within $20 \mathrm{~min}$ of anesthesia. The water-jacketed apparatus was bathed at $40^{\circ} \mathrm{C}$ by a circulating water bath (model 2161, Forma Scientific, Marietta, $\mathrm{OH})$. The mucosal and serosal sides were individually bathed in Ringer's solution oxygenated with $95 \% \mathrm{O}_{2}: 5 \% \mathrm{CO}_{2}$ via a glass 
bubble-lift apparatus (World Precision Instruments, Sarasota, FL).

Study 1: Transepithelial Lactose Flux from Colon and Jejunum. Four jejunal and four colonic tissues from each of five piglets were mounted under short-circuited conditions using a four-electrode automatic voltage clamp, capable of measuring transepithelial potential difference and automatically subtracting fluid resistance (DVC 1000, World Precision Instruments). Tissues were allowed to equilibrate for $30 \mathrm{~min}$ before cold and $\left[\mathrm{U}^{14} \mathrm{C}\right]$ lactose were added to the mucosal bath (11). To maintain transepithelial isotonicity, an equal amount (mol) of mannitol was added to the serosal bath. The added lactose was sufficient to achieve a final concentration of either $10 \mathrm{mM}$ or $40 \mathrm{mM}$ in separate tissues and corresponding sp act of $0.02 \mu \mathrm{Ci} / \mathrm{mmol}$ and $0.005 \mu \mathrm{Ci} / \mathrm{mmol}$. Thus, although there was not an osmotic gradient between mucosal and serosal compartments, there was a lactose concentration gradient. The final mucosal and serosal osmolality was adjusted to 360 mosmol with mannitol; this value is representative of the osmolality in the colon during the first week of life (12). The transport study was allowed to proceed for $60 \mathrm{~min}$.

The following assays were performed and are described in detail below. $\mathrm{R}_{\mathrm{t}}$ and $\mathrm{I}_{\mathrm{sc}}$ were measured. Flux of lactose was calculated from measured dpm in the serosal bath. The amount of serosal lactose, glucose, and galactose was determined by TLC and colorimetry. Tissue accumulation of ${ }^{14} \mathrm{C}$ was determined by scintillation counting of solubilized specimens of exposed tissues.

Study 2: Saturability of Lactose Absorption. To assess the saturability of the lactose transport mechanism, the same conditions as those in study 1 were repeated using six concentrations of lactose in the mucosal bath of mounted colonic tissues: 1, 5, $10,20,30$, and $40 \mathrm{mM}$. A $10-\mathrm{mM}(4 \mathrm{~g} / \mathrm{L})$ solution of PEG 400 (molecular mass 150-590 D; the value of $10 \mathrm{mM}$ was based on the average molecular mass of $400 \mathrm{D})$ was added to the mucosal bath as a marker of paracellular permeability. Osmolality was balanced in the serosal bath with mannitol. Flux of lactose was determined as in study 1 . To measure PEG movement, the serosal fluid was analyzed for individual oligomers and the flux (in $\mathrm{nmol} \cdot \mathrm{cm}^{-2} \cdot \mathrm{h}^{-1}$ ) calculated, as detailed below.

Study 3: Absorption of Lactose under Nongradient Conditions. Lactose flux in studies 1 and 2 occurred under gradient conditions for the sugar. To examine the possibility that the transport process was active, in this experiment, the lactose gradient was abolished. Matched colonic tissue pairs, differing in resistance by no more than $25 \%$, were used to measure unidirectional flux $\left(\mathrm{J}_{\mathrm{m} \rightarrow \mathrm{s}}\right.$ and $\left.\mathrm{J}_{\mathrm{s} \rightarrow \mathrm{m}}\right)$ with $\left[{ }^{14} \mathrm{C}\right]$ lactose $(0.02 \mu \mathrm{Ci} / \mathrm{mmol})$ added to either the mucosal or serosal test bath. Net flux was determined by subtracting $\mathrm{J}_{\mathrm{s} \rightarrow \mathrm{m}}$ from $\mathrm{J}_{\mathrm{m} \rightarrow \mathrm{s}}$.

Assays. Tissue viability. Tissues were deemed viable if the $\mathrm{R}_{\mathrm{t}}$ remained unchanged during the study, if theophylline caused an immediate increase in $\mathrm{I}_{\mathrm{sc}}$ when added to the circulating bath at the end of the study, and if the PEG 400 and carbohydrates present did not equilibrate with the concentrations in the contralateral bath.

Electrophysiologic measurements. $\mathrm{R}_{\mathrm{t}}$ and $\mathrm{I}_{\mathrm{sc}}$ were calculated as previously detailed (11). Data from each chamber were graphically recorded (Linear Instruments, Houston, TX); the data from all eight chambers were simultaneously collected and stored using an IBM PC-XT computer with analog to digital converters.

Flux measurements. The tissue was equilibrated in buffer for $30 \mathrm{~min}$. After labeled and unlabeled lactose were added to the bath, a $5-\mathrm{min}$ circulation period was allowed before a $0.5-\mathrm{mL}$ baseline ( 0 time) aliquot was withdrawn from both baths. One sample $(0.5-\mathrm{mL})$ was stored for later analysis in $50 \mu \mathrm{L}$ of $2 \mathrm{~N}$ $\mathrm{NaOH}$ to prevent bacterial digestion (13). After $60 \mathrm{~min}$, another $0.5-\mathrm{mL}$ sample was withdrawn from each bath and treated in the same manner. Another set of 0- and 60-min samples were immediately processed for scintillation counting (Tri-Carb 2200 CA, Packard Instruments, Downers Grove, IL) to assess tissue integrity. Samples that showed equilibration between mucosal and serosal dpm of ${ }^{3} \mathrm{H}$ or ${ }^{14} \mathrm{C}$ were deemed punctured, and the data from that tissue were discarded.

To measure the flux of lactose, the entire serosal solution was drained into a tared vial containing $1 \mathrm{~mL}$ of $2 \mathrm{~N} \mathrm{NaOH}$. The solution was weighed, desalted over a $1 \times 20 \mathrm{~cm}$ column of Amberlite MB3 (a mixed cationic/anionic resin) that was washed with 7 to 10 volumes of deionized water. The effluent was lyophilized to dryness and reconstituted in $1 \mathrm{~mL}$ of distilled water. The results from scintillation counting were used to calculate flux using standard calculations (11).

Carbohydrate assays. After incubation, aliquots of mucosal fluid $(10 \mu \mathrm{L})$ were removed to quantitate mucosal accumulation of glucose and galactose, formed by the enzymatic hydrolysis of lactose; they were assayed by TLC (LK5D silica gel plates, Whatman, Clifton, $\mathrm{NJ})$, as described in previous reports $(11,13$, 14). The plates were developed with butanol:acetone:water $(5: 4: 1$ $\mathrm{vol} / \mathrm{vol}$ ) and stained with an anisaldehyde reagent (15). This stain detects as little as $1 \mu \mathrm{g}(5.5 \mathrm{nmol})$ of glucose without interference from mannitol.

To quantitate the concentrations of the three carbohydrates in the serosal bath, the following procedure was used. After the entire serosal bath was lyophilized to dryness and reconstituted in water twice, a 50-100 $\times$ concentration of the serosal bath solution was achieved. A $10-\mu \mathrm{L}$ aliquot was analyzed by the phenol sulfuric acid colorimetric method for total carbohydrate concentration (16). A second $10-\mu \mathrm{L}$ sample was applied to a TLC plate; the adjacent lane contained lactose, glucose, and galactose standards. The plate was developed and dried. The sites of the individual carbohydrates were identified on the lanes with standards, and the sites were marked on the remaining (unstained) lanes. The silica gel within each identified area was scraped into a test tube and subjected to the phenol sulfuric acid assay. In this way, the quantity and ratio of the three test carbohydrates and the total carbohydrate in the serosal bath was calculated. Although the TLC method could visualize a spot containing as little as $5.5 \mathrm{nmol}(1 \mu \mathrm{g})$ of glucose on the silica gel, the phenol sulfuric acid method of analyzing silica gel spots was not accurate below $20 \mathrm{nmol}(4 \mu \mathrm{g})$ glucose. Because the serosal bath was completely recovered and concentrated 50 - to 100 -fold, the sensitivity of the TLC/phenol sulfuric acid assay was deemed ample for the quantification of carbohydrate in these studies.

Tissue accumulation of ${ }^{14} \mathrm{C}$ or ${ }^{3} \mathrm{H}$. The portion of the mounted jejunal and colonic tissue that was exposed to the incubation baths was carefully excised from the lucite chambers and blotted on filter paper. After weighing, a portion was removed for protein analysis. The tissue was solubilized (Soluene 350, Packard) overnight in a $60^{\circ} \mathrm{C}$ water bath and the dpm were quantified with Hionic-Fluor (Packard), with the aid of a program for dual-label analysis of ${ }^{3} \mathrm{H}$ and ${ }^{14} \mathrm{C}$. Counts were normalized per mg of tissue protein, using a modification of the Bradford method (17).

$P E G$ profile. PEG movement was assayed in study 2 to determine whether varying concentrations of lactose from 1 to 40 $\mathrm{mM}$ could stimulate paracellular diffusion. A $0.5-\mathrm{mL}$ aliquot of the serosal bath was removed and lyophilyzed (10x concentration) for analysis of the PEG flux, as previously described (18, 19). After desalting, HPLC (HP 1050 with an HP 1047 refractive index detector, Hewlett-Packard, Palo Alto, CA; Waters C18 column, Milford, MA; eluant: methanol: $\mathrm{H}_{2} \mathrm{O} 1: 3$, vol/vol) was used to separate and quantify the eight individual serosal PEG oligomers in relation to a standard curve generated by a set of external standards. To identify at least five of the PEG oligomers, a serosal bath concentration of $5 \mathrm{nmol} / \mathrm{mL}$ of PEG was necessary; this represents a lower limit of detection for PEG flux of $45 \mathrm{nmol} \cdot \mathrm{cm}^{-2} \cdot \mathrm{h}^{-1}$. When the serosal bath sample was lyophilized, the lower limit of detection for PEG flux was $0.45 \mathrm{nmol}$. $\mathrm{cm}^{-2} \cdot \mathrm{h}^{-1}$. The lactose flux was determined in the same $0.5-\mathrm{mL}$ sample to compare with the PEG flux.

Materials. Lactose, glucose, galactose, and mannitol were obtained from Sigma Chemical Co., St. Louis, MO. PEG 400 was purchased from Fisher Scientific, Fairlawn, NJ. The $\left[\mathrm{U}-{ }^{14} \mathrm{C}\right]$ 
lactose was purchased from New England Nuclear Dow Research Products, Boston, MA. Amberlite MB3, a mixed-bed resin, is a product of Mallinckrodt, Paris, KY.

Statistics. Results are expressed as means \pm SEM. Statistical analysis was performed using both paired and unpaired $t$ test where appropriate. A one-way analysis of variance was used to compare lactose flux with lactose concentration. Linear regression of the log values was also used to confirm that lactose flux was a linear function with respect to lactose concentration; $p$ values $<0.05$ were considered significant.

\section{RESULTS}

Study 1: Flux of Lactose in Jejunum and Colon. Flux of lactose. The unidirectional flux of lactose in the jejunum and in the colon is presented in Table 1 . The magnitude of colonic $\mathrm{J}_{\mathrm{m} \rightarrow \mathrm{s}}$ in the presence of $10 \mathrm{mM}$ lactose $\left(500 \pm 100 \mathrm{nmol} \cdot \mathrm{cm}^{-2} \cdot \mathrm{h}^{-1}\right)$ and in the presence of $40 \mathrm{mM}$ lactose $\left(1431 \pm 190 \mathrm{nmol} \cdot \mathrm{cm}^{-2} \cdot \mathrm{h}^{-1}\right)$ was similar to that of lactose-derived glucose observed in the jejunum $\left(560 \pm 80\right.$ and $1710 \pm 260 \mathrm{nmol} \cdot \mathrm{cm}^{-2} \cdot \mathrm{h}^{-1}$ in the presence of 10 and $40 \mathrm{mM}$, respectively).

Tissue accumulation. Although accumulation of counts was substantial, no tissue contained more than $5 \%$ of the original ${ }^{14} \mathrm{C}$ that had been placed in the mucosal bath (maximum, $18.5 \mathrm{nmol}$ lactose/mg protein). There was no further accumulation of ${ }^{14} \mathrm{C}$ in jejunal and colonic tissues exposed to $40 \mathrm{mM}$ when compared with those exposed to $10 \mathrm{mM}$ lactose.

Electrophysiologic data. Despite similarities in $\mathrm{J}_{\mathrm{m} \rightarrow \mathrm{s}}$ and in tissue retention of lactose between the two intestinal segments, only the jejunum showed a significant increase in $\mathrm{I}_{s c}$ in the presence of mucosal lactose $\left(11 \pm 1.6\right.$ and $25 \pm 5.7 \mu \mathrm{A} \cdot \mathrm{cm}^{-2}$ for 10 and $40 \mathrm{mM}$, respectively). The values for $\mathrm{I}_{\mathrm{sc}}$ were similar to those reported by other investigators (20) using newborn suckled piglet ileum.

Carbohydrate analysis. Analysis of the serosal solution for carbohydrates indicates a difference in the fate of lactose incubated with jejunal or colonic tissues. Figure $1 A$ and $B$ shows the accumulated carbohydrate species on both serosal and mucosal baths surrounding the jejunal and colonic tissues after $60 \mathrm{~min}$ of mucosal exposure to $10 \mathrm{mM}$ lactose. In the serosal (contralateral) bath of the jejunal specimens, the carbohydrate identified was glucose (Fig. 1A). By contrast, in the serosal baths of the colonic specimens, intact lactose accounted for over $95 \%$ of the transported carbohydrate. Galactose was not identified on any of the TLC plates. Analysis of the mucosal samples showed that, when jejunal tissue was exposed to lactose, glucose and galactose accumulated on the mucosal side; when colonic tissues were exposed to lactose, monosaccharides did not accumulate on the mucosal side (Fig. 1B).

Study 2: Saturability of Lactose Absorption. Flux data. The flux of lactose did not show saturation up to a concentration of $40 \mathrm{mM}$ (Fig. 2). By one-way analysis of variance, the lactose flux was a function of lactose concentration $(p<0.001)$. A linear relationship between the log of flux and concentration was seen

Table 1. Unidirectional carbohydrate flux from 10- and 40-mM mucosal lactose solutions under voltage clamped conditions in isolated newborn porcine jejunum and colon*

\begin{tabular}{ccccc}
\hline & $n$ & $\mathrm{I}_{\mathrm{sc}}$ & $\mathrm{R}_{\mathrm{t}}$ & $\mathrm{J}_{\mathrm{m} \rightarrow \mathrm{s}}$ \\
\hline Jejunum & & & & \\
$10 \mathrm{mM}$ & 10 & $11 \pm 1.6$ & $35.7 \pm 5.7$ & $560 \pm 80$ \\
$40 \mathrm{mM}$ & 10 & $25 \pm 5.7$ & $37.8 \pm 5.7$ & $1710 \pm 260$ \\
Colon & & & & \\
$10 \mathrm{mM}$ & 10 & $3 \pm 2.1$ & $60.6 \pm 7.2$ & $500 \pm 100$ \\
$40 \mathrm{mM}$ & 10 & $-2 \pm 2.7$ & $54.8 \pm 2.7$ & $1431 \pm 190$ \\
\hline
\end{tabular}

* Values are means \pm SEM of five animals; $n=$ no. of tissues. $\mathrm{I}_{\mathrm{sc}}(\mu \mathrm{A}$. $\mathrm{cm}^{-2}$ ) represents the difference between baseline (steady state) and maximal stimulation after the addition of lactose to the mucosal bath. $\mathrm{J}_{\mathrm{m} \rightarrow \mathrm{s}}$ is reported in $\mathrm{nmol} \cdot \mathrm{h}^{-1} \cdot \mathrm{cm}^{-2} ; \mathrm{R}_{\mathrm{t}}$ is reported in $\mathrm{ohm} \cdot \mathrm{cm}^{2}$.

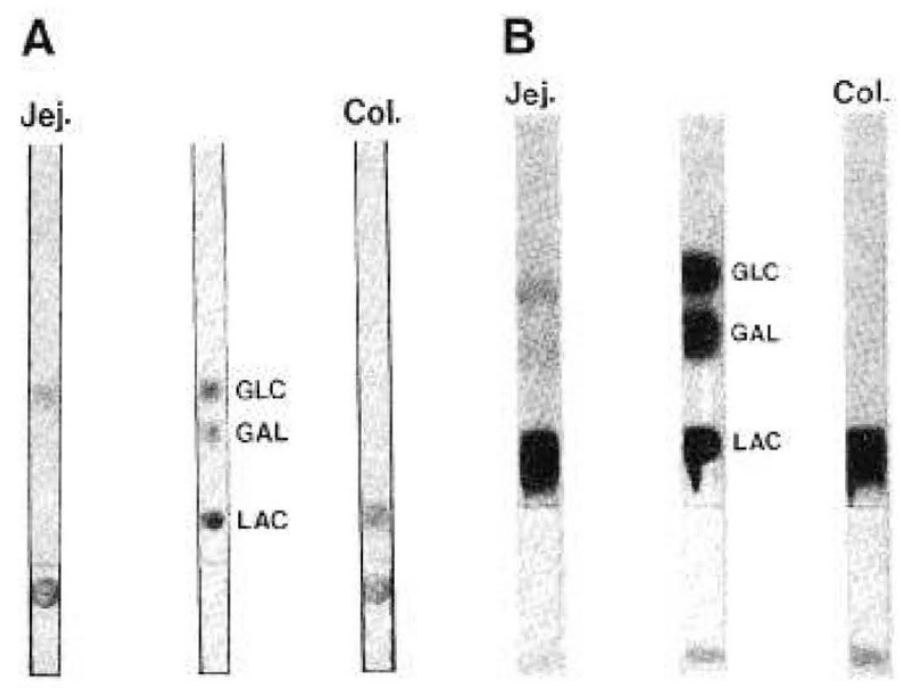

Fig. 1. Representative TLC showing the carbohydrates that accumulated in the serosal bath during studies in which lactose $(10 \mathrm{mM})$ was incubated in the mucosal bath. After a 60 -min incubation, the serosal bath was collected, lyophilized, and reconstituted in water (approximately a $50 \times$ concentration); a $10-\mu \mathrm{L}$ sample was applied to the diatomaceous preabsorbant area of the silica gel thin-layer plates. After separation by solvent, the carbohydrates, glucose $(G L C)$, galactose $(G A L)$, and lactose $(L A C)$, were stained with an anisaldehyde reagent. The presence of as little as $1 \mu \mathrm{g}(5.5 \mathrm{nmol})$ of glucose can be visually appreciated by this method. $A$, serosal samples after 60 -min incubations with jejunum and with colon. The center lane contains the control carbohydrates for reference. $B$, mucosal samples collected after incubation, showing the effects of mucosal enzyme activity on lactose in the jejunal but not the colonic tissues.

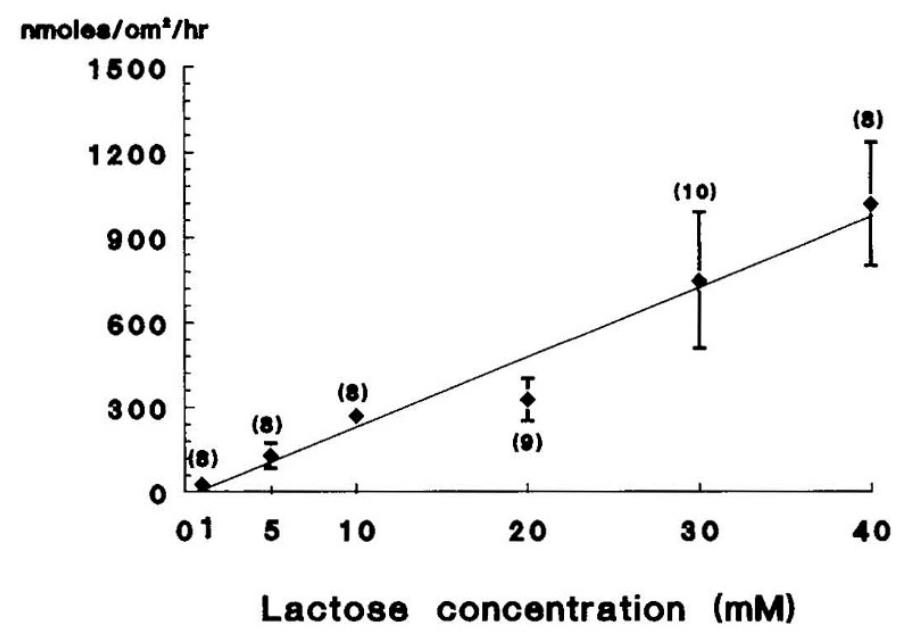

Fig. 2. The relationship between increasing lactose concentration and lactose flux. All values represent mean \pm SEM from eight or more tissues (number in parentheses) obtained from three or more 4-d-old piglets. The flux of lactose was related to the lactose concentration $(p<0.001)$, and their relationship was linear $(r=0.944)$ within the concentration range tested.

$(r=0.944)$, with no indication of an asymptote to suggest saturation within the range of concentrations tested (not shown).

PEG profile. Movement of PEG 400 oligomers across the mucosa to the serosal bath was not detected, despite a 1-h incubation. The lower limit of detection for PEG flux, using the HPLC methodology, was $45 \mathrm{nmol} \cdot \mathrm{cm}^{-2} \cdot \mathrm{h}^{-1}$. A 10 -fold concentration of the serosal bath also did not reveal any PEG peaks; therefore, the flux of PEG $\left(<0.45 \mathrm{nmol} \cdot \mathrm{cm}^{-2} \cdot \mathrm{h}^{-1}\right)$ was at least 1000 -fold less than the flux of lactose (a mean of $500 \mathrm{nmol}$. $\left.\mathrm{cm}^{-2} \cdot \mathrm{h}^{-1}\right)$. 
Study 3: Absorption of Lactose under Nongradient Conditions. Comparisons between the jejunum and colon are presented for $\mathrm{J}_{\mathrm{m} \rightarrow \mathrm{s}}, \mathrm{J}_{\mathrm{s} \rightarrow \mathrm{m}}$, and net flux in Table 2 . As expected, an appreciable net flux $\left(680 \mathrm{nmol} \cdot \mathrm{cm}^{-2} \cdot \mathrm{h}^{-1}\right)$ of lactose-derived glucose remained across the jejunal tissues despite the elimination of the gradient for lactose, whereas net lactose flux across the colonic tissues was completely abolished when the lactose gradient was absent. Differences in the net lactose flux between the jejunal and colonic tissues were significant $(p<0.01)$.

\section{DISCUSSION}

Cumulatively, the results of these studies demonstrate that the colon of the newborn pig can transport intact lactose from the mucosal to the serosal bath by a mechanism that does not require enzymatic cleavage of lactose, generate an $I_{s c}$, or appear to be carrier-mediated and yet does not appear to occur by a process of nonselective paracellular diffusion.

In a previous study, we used in vivo perfusions in piglets up to $25 \mathrm{~d}$ of age to demonstrate that lactose was absorbed from the colon 20 times faster than glucose and galactose from a solution that was equimolar in terms of hexose moieties (8). The mechanism of lactose absorption from the colon did not appear to involve $\beta$-galactosidase activity or fermentation. The in vitro study reported in this manuscript extends our previous findings. The data confirmed that lactose absorption occurred from the colon when measured directly as serosal appearance (flux) rather than indirectly as disappearance from the colonic lumen. The results further demonstrated that the transported species was the disaccharide, lactose, and not cleavage products (glucose and galactose) or fermentation products (short-chain fatty acids). The restricted movement of PEG 400, a well-characterized marker for passive colonic permeability, and of glucose and galactose, supported the idea that the uptake of lactose was a selective process.

The mechanism responsible for transport of intact lactose across the colon in newborns could involve a membrane transport carrier different from that of the small intestine; paracellular movement (i.e. by mass transport); transcellular transport (i.e. by endocytosis); or some other, as yet undefined, process. Active transport processes, such as the glucose carrier in the small intestine, demonstrate saturability, energy dependence, and net flux against a concentration gradient. Potter et al. (21) reported glucose transport during colonic perfusion in rats immediately after birth. Similarly, Henin and Smith (22) showed that neonatal piglet colon is capable of phlorizin-sensitive electrogenic transport of glucose in the first hours of life, a process analogous to that seen in the jejunum; however, the mechanism disappeared by the second day of life. In our study on 4-d-old piglets, colonic lactose transport was not saturable and did not result in net movement when the concentration gradient was abolished. Therefore, carrier-mediated active transport is unlikely. Simple diffusion, which would favor transport of smaller molecular weight substances, is also unlikely. Although lactose (molecular mass $342 \mathrm{D}$ ) was transported in colon, smaller oligomers such as glucose (molecular mass $180 \mathrm{D}$ ) and PEG oligomers (molecular mass $<342 \mathrm{D}$ ) were not found in the serosal bath, suggesting that indiscriminant paracellular movement did not occur.

Table 2. Net carbohydrate flux from 10-mM lactose solution under nongradient conditions in isolated newborn porcine jejunum and colon*

\begin{tabular}{lcccc}
\hline & $n$ & $\mathrm{~J}_{\mathrm{m} \rightarrow \mathrm{s}}$ & $\mathrm{J}_{\mathrm{s} \rightarrow \mathrm{m}}$ & $\mathrm{J}_{\text {net }}$ \\
\hline Jejunum & 29 & $869 \pm 89$ & $396 \pm 60$ & $608 \pm 91$ \\
Colon & 25 & $246 \pm 47$ & $275 \pm 32$ & $-30 \pm 22$ \\
\hline
\end{tabular}

*Values are means \pm SEM from eight animals; $n=$ no. of tissues. $J_{\text {net }}$, the difference between $J_{m \rightarrow s}$ and $J_{s \rightarrow m} . J_{m \rightarrow s}, J_{s \rightarrow m}$, and $J_{\text {net }}$ are reported in $\mathrm{nmol} \cdot \mathrm{h}^{-1} \cdot \mathrm{cm}^{-2}$. Differences in the $J_{\text {net }}$ between the jejunal and colonic tissues were significant $(p<0.008)$
Passive movement of intact disaccharide could be postulated to occur through the tight junctions between the colonocytes. A model for the paracellular transport has been proposed for the small intestine, suggesting that the bulk of luminal glucose and amino acids is absorbed by passage through the tight junctions $(23,24)$. This process is believed to be initiated by the active transport of glucose which, by creating an osmotic gradient between the intercellular space and the intestinal lumen, stimulates contraction of the cytoskeletal proteins and opening of the intercellular tight junctions. The open channel allows hydrophilic nutrients to pass between the cells in association with water flow. In their studies, Pappenheimer and Reiss (25) used passively absorbed markers, including creatinine (molecular mass $113 \mathrm{D}$ ), PEG (molecular mass $4000 \mathrm{D}$ ), phenolsulfonphthalein (molecular mass $342 \mathrm{D}$ ), and inulin (molecular mass $5500 \mathrm{D}$ ), to demonstrate a nonselective paracellular movement associated with fluid absorption. These investigators used an in vivo perfusion model with glucose $(25 \mathrm{mM})$ as the actively transported species.

To test the hypothesis that paracellular diffusion accounts for passage of lactose across the colonic mucosa, we included PEG 400 , a mixture of nonmetabolizable ethylene glycol oligomers with a molecular mass range of 150 to $590 \mathrm{D}$. PEG 400 permeation of the colonic mucosa has been shown to be mediated almost exclusively by paracellular diffusion (26). The molecular masses of the oligomers in PEG 400 span those of glucose and galactose (molecular mass $180 \mathrm{D}$ ) and lactose (molecular mass 342 D). In our studies, the flux of the disaccharide was tested between 1 and $40 \mathrm{mM}$, values that represent the range of physiologic luminal concentrations, to test the putative opening of intercellular channels $(23,27)$. PEG was not found in the serosa bath even when the bath was concentrated 10 -fold; nonetheless, the disaccharide passed into the serosal bath at a rate equal to that of lactose-derived glucose in the jejunum. Therefore, on a molar basis, PEG passage was at least 1000 -fold less than the movement of lactose. These findings suggest that nonselective sieve-like intercellular movement is not likely to be the explanation for lactose transport in our studies.

An alternative transport route, transcellular endocytosis, could account for the appearance of intact lactose. Evidence exists for an active endocytic process in the principle cells of the colon in the newborn rat. Ono (28) has shown by electron microscopy that a tubulovesicular network with lysosomal granules is present in the first days of life but disappears by the end of the first week. Molecules as large as horseradish peroxidase (molecular mass $160000 \mathrm{D})$ were transported by this network in the colon of the 4- to 5-d-old rat (29). In piglets and in human neonates, a similar intracellular transport system can be found in the small intestine and colon in the late fetal and immediate neonatal period (30, 31). More definitive studies on endocytosis as a means of lactose transport are not feasible on mounted tissues in the Ussing chamber.

Our TLC data from the jejunal controls are somewhat surprising. In the serosal bath of the jejunum, lactose-derived glucose was the sole species identified. The absence of galactose suggests that after the digestion of lactose occurs at the small-bowel mucosal surface, galactose undergoes another metabolic step: either further digestion, utilization, or epimerization to glucose. Studies in human newborns ingesting lactose have shown that galactose is present in blood in much lower amounts than glucose after a lactose meal, a finding that has been attributed to avid first-pass clearance through the liver (32). Metabolism of galactose or its epimerization to glucose before exit from the enterocyte might be alternative explanations for low-serum galactose levels under such conditions.

In summary, these studies provide evidence for a functional lactose transport process in the colon of the newborn pig. The rate of transport is significant-equal to that of lactose-derived glucose in the jejunum. However, the mechanism of colonic transport of lactose appears distinct from that in the small 
intestine. Under physiologic conditions, i.e. in the presence of a normal colonic bacterial flora, such a transport system may not be extensively utilized. But when the bacterial flora are depleted, such as occurs during diarrhea, after antibiotics, or in the first days of life, such a transport process may enable the newborn to salvage lactose that escapes assimilation in the small intestine and prevent a potentially lethal osmotic diarrhea (33).

\section{REFERENCES}

1. Auricchio S, Rubino A, Murset G 1965 Intestinal glycosidase activities in the human embryo, fetus, and newborn. Pediatrics 35:944-954

2. Kien CL, Liechty EA, Myerberg DZ, Mullett MD 1987 Dietary carbohydrate assimilation in the premature infant: evidence for a nutritionally significant bacterial ecosystem in the colon. Am $\mathbf{J}$ Clin Nutr 46:456-460

3. MacLean Jr WC, Fink BB 1980 Lactose malabsorption by premature infants: magnitude and clinical significance. J Pediatr 97:383-388

4. MacLean Jr WC, Fink BB, Schoeller DA, Wong W, Klein PD 1983 Lactose assimilation by full-term infants: relation of $\left[{ }^{13} \mathrm{C}\right]$ and $\mathrm{H}_{2}$ breath tests with fecal $\left[{ }^{13} \mathrm{C}\right]$ excretion. Pediatr Res 17:629-633

5. Murray RD, Boutton TW, Klein PD, Gilbert M, Paule CL, MacLean Jr WC 1990 Comparative absorption of $\left[{ }^{13} \mathrm{C}\right]$ glucose and $\left[{ }^{13} \mathrm{C}\right]$ lactose by premature infants. Am J Clin Nutr 51:59-66

6. Modler S, Kerner Jr JS, Castillo RO, Vreman HJ, Stevenson DK 1988 Relationship between breath and total body hydrogen excretion rates in neonates. J Pediatr Gastroenterol Nutr 7:554-558

7. Potter G 1989 Development of colon function. In: Lebenthal E (ed) Human Gastrointestinal Development, 2nd Ed. Raven, New York, pp 555-563

8. Murray RD, Ailabouni A, Powers P, McClung HJ, Li BUK, Heitlinger LA, Sloan HR 1991 Absorption of lactose from the colon of the newborn piglet. Am J Physiol 261:G1-G8

9. Sundqvist T, Magnusson K-E, Sjodahl R, Stjernstrom I, Tagesson C 1980 Passage of molecules through the wall of the gastrointestinal tract: application of low-molecular weight polyethyleneglycol and a deterministic mathematical model for determining intestinal permeability in man. Gut 21:208-214

10. Tagesson C, Sjohahl R 1984 Passage of molecules through the wall of the gastrointestinal tract: urinary recovery of different-sized polyethylene glycols after intravenous and intestinal deposition. Scand J Gastroenterol 19:315320

11. Heitlinger LA, Li BUK, Murray RD, McClung HJ, Sloan HR, DeVore DR 1991 Glucose flux from dietary disaccharides: all sugars are not absorbed at equal rates. Am J Physiol 261:G818-G822

12. Murray RD, McClung HJ, Li BUK, Ailabouni TA 1987 Short-chain fatty acid profile in the colon of newborn piglets using fecal water analysis. Pediatr Res 22:720-724

13. Murray RD, Ailabouni A, Powers PA, McClung HJ, Li BUK, Heitlinger LA, Sloan HR 1990 Failure to conserve lactose and glucose polymers during frozen storage of fecal specimens: methods for preservation. Clin Chim Acta 192:181-190
14. Murray RD, Kerzner B, Sloan HR, McClung HJ, Ailabouni TA 1986 The contribution of salivary amylase to glucose polymer hydrolysis in prematures. Pediatr Res 20:186-191

15. Kwiterovich PO, Sloan HR, Frederickson DS 1970 Glycolipids and their lipid constituents of normal human liver. J Lipid Res 11:322-329

16. Dubois M, Gilles KA, Hamilton JD, Rebers PA, Smith F 1956 Colorimetric method for determination of sugars and related substances. Anal Chem 28:350-356

17. Bradford MM 1976 A rapid and sensitive method for the quantitation of microgram quantities of protein utilizing the principle of protein-dye binding. Anal Biochem 72:248-254

18. McClung HJ, Sloan HR, Powers P, Merola J, Murray RD, Kerzner B, Pollack JD 1990 Early changes in the permeability of the blood-brain barrier produced by toxins associated with liver failure. Pediatr Res 28:227-231

19. Sloan HR, McClung HJ, Powers P, Kerzner B 1983 Thin-layer and gel permeation chromatographic separation of low molecular weight polyethylene glycol oligomers. Clin Chim Acta 134:255-264

20. DeJesus H, Smith MW 1974 Sodium transport by the small intestine of the newborn and suckled pig. J Physiol 243:211-224

21. Potter GD, Schmidt KL, Lester R 1983 Glucose absorption by in vitro perfused colon of the fetal rat. Am J Physiol 245:424-430

22. Henin S, Smith MW 1976 Electrical properties of pig colonic mucosa measured during early post-natal development. J Physiol 262:151-168

23. Madara JL, Pappenheimer JR 1987 Structural basis for physiological regulation of paracellular pathways in intestinal epithelia. J Membr Biol 100:149-164

24. Pappenheimer JR 1990 Paracellular intestinal absorption of glucose, creatinine and mannitol in normal animals: relation to body size. Am J Physiol 259:G290-G299

25. Pappenheimer JR, Reiss KZ 1987 Contribution of solvent drag through intercellular junctions to absorption of nutrients by the small intestine of the rat. J Membr Biol 100:123-136

26. Krugliak P, Hollander D, Schlaepfer CC, Katz KD, Dadufalza VD, Ma TY 1990 Polyethylene glycol 400 penetration of the colonic epithelial barrier of the rat. Gastroenterology 99:1001-1007

27. Ferraris BP, Yasharpour S, Lloyd KCK, Mirzayan R, Diamond JM 1990 Luminal glucose concentration in the gut under normal conditions. Am J Physiol 259:G822-G837

28. Ono K 1976 Ultrastructure of the surface principal cells of the large intestine in postnatal developing rats. Anat Embryol 149:155-171

29. Ono K 1977 Absorption of horseradish peroxidase by the principal cells of the large intestines of postnatal developing rats. Anat Embryol 151:53-62

30. Bell L, Williams L 1982 A scanning and transmission electron microscopical study of the morphogenesis of human colonic villi. Anat Embryol 165:437455

31. Jarvis LG, Morgan G, Smith MW, Wooding FB 1977 Cell replacement and changing transport function in the neonatal pig colon. J Physiol (Lond) 273:717-729

32. Siegel CD, Sparks JW, Battaglia FC 1988 Patterns of serum glucose and galactose concentrations in term newborn infants after milk feeding. Biol Neonate 54:301-306

33. Argenzio RA, Moon HW, Kemeny LJ, Whipp SC 1984 Colonic compensation in transmissible gastroenteritis of swine. Gastroenterology. 86:1501-1509 